Journal of Social Sciences 7 (4): 655-661, 2011

ISSN 1549-3652

(C) 2011 Science Publications

\title{
Rural Population Density Effect on Socio-economic Characteristics: A Review
}

\author{
Ayoob Khaleel Ismael and Ibrahim Ngah \\ Department of Urban and Regional Planning, Faculty of Built Environment, \\ University Technology Malaysia, 81310, Skudai, Johor, Malaysia
}

\begin{abstract}
Problem statement: Rural population density has a very significant independent influence over important demographic and socio-economic characteristics of the world rural communities. Thus, the understanding of rural population density becomes an important issue to be studied. Approach: Using the rural settled areas of Shaqlawa District as a case study, this study seeks to reveal the specific importance of rural population density as an important variable in understanding the socioeconomic characteristics of sparsely settled rural regions, where spares and falling density presents practical and conceptual problems for rural planners. Results and Conclusion: It is obvious that the need of rural areas for socioeconomic development and regeneration along with the need for diversification of their economic base so as to meet the changes is today greater than ever. The motivation behind of this project is based on the fact that during the last few decades the rural settlement in the study area has been dramatically changed. However at the same time there is a realization that certain parts of the rural area have been left behind in development and the authority is currently promoting rural area in order to sustain local economies and to enhance employment and growth.
\end{abstract}

Key words: Rural population density, rural community, shaqlawa distirct, socioeconomic characteristics, under developed nations, dramatically changed, specific measurement, particular environment, Gross Domestic Product (GDP)

\section{INTRODUCTION}

A look at the various developing and developed nations worldwide will clearly show that some of the developed nations like Canada or Australia are placed at the extreme end in the list of the gross national population densities. In these countries having extremely low population rates large tracts of areas remain practically uninhabited, though observations reveal that their 'pre-urban' (urban fringes) population densities around the large urban centers are more or less similar to the other developed nations. This has led to a dense rural population in certain 'pockets' (around the metropolitan centers) within the country, presenting a host of problems, both theoretically and practically, for the rural policy makers and developers. Besides the infrastructural and developmental problems, observations also show that a spatially constrained antithetical urbanization movement has allowed the entry of certain 'exurban' elements within the sphere of some of the rural communities, thus making it necessary that one makes a review of the entire situation from a new perspective. A closer look at the available research study will reveal that though are some researches on the subject of urban population densities, with some study exploring the falling densities in rural areas, there is a serious lack of data on the effects of the rising or falling rural population densities on the socio-economic characteristics of the rural communities.

Existing study on rural population density: Rural population density is a very specific measurement of the population of a rural area-which includes regional open space, agriculture and water-bodies-excluding urban land-uses. And the term is used in rural planning to refer to the number of people inhabiting a given rural area. As such it is to be distinguished from other measures of population density, rural density is considered an important factor in understanding how settlements function. Study related to rural density occurs across diverse areas, including economics, health, innovation, psychology and geography as well as sustainability. Human population density (both urban and rural) serves as an important study tool, necessary to measure the balance between the total capacity of the physical

Corresponding Author: Ayoob Khaleel Ismael, Department of Urban and Regional Planning, Faculty of Built Environment, University Technology Malaysia, 81310, Skudai, Johor, Malaysia 


\section{J. Social Sci., 7 (4): 655-661, 2011}

environment necessary to support the perpetually rising global population, especially in the context of the developing or under developed nations. The studies on population density have primarily focused on the constantly increasing human population and subsequent impact of this increase on the physical environment and the resources available. The picture of an increasing population in developing nations, inserting compelling pressure on the country's natural resources, takes a different turn in majority of the developed industrialized nations. Here, researches show that the excessive low human population densities may show detrimental effects on the support system of social communities within the modern, industrialized, capitalist societies, creating barriers in the scale economy development, restraining the division of labor, while reflecting a heavy transportation charges upon the rural and 'sparseland' populations, that decrease their chances for social interactions (Theodoropoulou and Panagiotis, 2008). Though having a seemingly simple front, the term population density actually comprises of a complex concept, which is associated with a wide range of factors like the physical environment, humans, economy and technology, with each factor closely linked to the other. In his study delineated two major concepts within the term population density, which are: measured density (a quantifiable figure of the population units, that comprise of the individuals, families and the households, in per unit area); and perceived density (a qualitative dimension comprising of abstract concepts, like loneliness, privacy, isolation, contact potential and crowding).

Human population density has always been the chief centralizing theme within geographical studies, corelating the range and depth of the interrelationships that occur between society, individuals and the surrounding physical environment and the nature of their mutual influence. a majority of the density related research study has centered upon the factor of measured density (ratio of people per unit area) and have explored various aspects seeking resolutions for problems related to the services provided by the State, or for planning, within rural or urban settings. Holmes (1981) in his study conceptualized the notions of 'critical density thresholds' for specific kind of service centre oriented network, where he associates population density levels to the wider aspects of 'primary production,' and his study on Australian population density distinguished between the 'sparselands' and the 'settled areas'.

A closer look at this subject revealed that not much study has been done in this line owing to the complex nature of the term population density (Fonseca and Wong, 2000). It is not easy to distinguish between cause and effect, while explaining the various planes of human density and the type and depth of their relationships with different social aspects. The complex nature of population density also implicates the involvement of the socio-economic, environmental and historical factors that help to create a specific density spectrum and kind, like, linear, clustered, or randomly distributed, in respect to any type of rural community Argent et al. (2005).

The perceived density or the qualitative dimensions of population density are yet to be explored in details. only a few researchers have worked in this regards, as for example, Irving and Davidson 1972 defined social density (interpersonal relationships between members of a rural community) Tuan (1977) in his study emphasized that the feelings of crowding or loneliness were created owing to an individual's sense of socioeconomic opportunity within a particular environment. He opined that qualitative responses to the figurative human population density were adapted by two main factors, culture and the desire for a community member's self-accomplishment. Here Tuan gives an example of the Russian farmers residing in the Steppes. This landscape does not have much human habitation, except for few isolated farmhouses and such isolation tends to produce a feeling of fear and despair within the local rural inhabitants (Tuan, 1977). Therefore, the subjective aspects of crowding or isolation though not directly related to the physical environment can nevertheless have a significant influence. In her study recounts her experiences of the Norwegian people living in urban settlements and her observations show that the Norway residents displayed an antipathy towards urban form of life, which grew from their age-old tradition of low-density settlement, thus making the Norwegians inherently prefer sparser settlements. Here, (Saglie, 1998) comments, "The ideal Norwegian way is to live scattered because Norwegians are 'lone wolves'... Norway has been a kingdom of small kings, with rural communities divided by topographical features". According to, the two aspects of density (measured and perceived) portray two different conceptions of space. Measured density arises from an absolute proportion of space (Kantian theory); whereas the perceived density ensues from social relationships, is relative in nature with a relational concept of space.

Tuan in his study observed that "Human beings require both space and place. Human lives are a dialectical movement between shelter and venture, attachment and freedom (Tuan, 1977). Thus, one can derive that loneliness is also essential for the appropriate functioning of a society; Tuan, further adds that the 


\section{J. Social Sci., 7 (4): 655-661, 2011}

population shift from rural areas to urban areas during the era of industrialization was owing mainly to the young population moving away to the 'less crowded' cities, from the close knit social bindings of the rural communities (ibid, 60). Smailes (1996) in his researches on the Australian rural communities identified three prime zones of human habitats, within the rural context:

- Peri-urban zone' (fringe areas) which form the 'core' area, with higher incomes and high population growth

- Cereals/ sheep belt' showing declining density, loss of service and poor income type; and

- Marginal pastoral zone' that is experiencing rising decline in demography, very poor incomes while low chances for variegation.

Population density, best described in terms of a typical spatial aspect, reflects the way in which human species have spread out and occupied the surface of the earth and is an extremely important factor in the study of social and population geography. A study of the available literature on the subject, as already mentioned, however reveals that there are very few detailed studies in this line, with the majority of study conducted concerning themselves with population density only within the urban areas. For example, we find townplanning reviews based on the population density by with various other general overviews, on the subject of urban population density (Bahr et al. 1992). As regards specific studies on the density of the rural areas, there are articles by Robinson et al. (1961) that explore the link between the rural farm densities and percentage of arable land, percentage of the land producing crop, percentage of rainfall and the distance from the nearest urban centre. In their study on rural population density categorized the Kansas rural areas by the perceived changes in the population density patterns over time. However, it was in 1967 that Berry in his research study first undertook a systematic study to distinguish the effects on the variation of density on an overall community settlement system. Working within the restraining framework of the inflexible concepts of the central place theory, Berry revealed in his study that the dimensions of the rural trade areas and service centers is linked to the wider aspect of the regional population density of which it is a part. Irrespective of the population density, the rural centers are apt to form a distinct spatial pyramid (Berry, 1967). With a decrease in the population density, the place dimension at each level of the pyramid also decreases, while there is an increase in the trade area sizes that seeks to compensate partially for the decreasing population density. Subsequently owing to these shifts and transitions, the specific forms of services seen at the lowest level of the spatial pyramid under conditions of high-density rural population will move a step up to the next higher level when population density decreases (ibid). Berry in his study conceptualized the presence of a 'phase shift' within the spatial emulations of the trade centers, with sudden breaks in the density, as noticed between the suburban areas and the rural areas bordering the urban centers; or between the broad care type of farming zones and irrigation areas. A less known study that examines rural density by Irving and Davidson, 1972 explores primarily the urban population but with distinct rural applicability. In this study, the authors brought in the concept of social density, which reflects the time of interpersonal interactions that are occurring within a given unit of area, per unit of time. Rural population density has an important influence over the demographic and socio-economic characteristics of the rural communities in all developed and developing countries. It is also the basic factor taken into consideration by the government while undertaking developmental planning and shaping public policies. Population density (rural and urban) is influenced by certain factors, like the, available environmental resources in a particular area, the time and form of colonization, which are transient in nature and tend to keep on changing over the years Irving and Davidson, 1972.

Rural population density has a significant amount of influence over the socio-economic characteristics of rural communities, which is on one hand a persistent process occurring through a long period over the years and on the other hand it is also ongoing process taking place at the present moment. Unlike urban size, rural density takes a direct measure of the rural community's living size and space, the habitability of the physical environment where it is located and the potential cost of transport for service delivery and other measures of maintaining contact and personal interaction between the rural people (Smailes et al., 2002). In Australia, researchers have shown that the besides the aforementioned factors rural density can be also corelated with 'age and maturity' of the rural community's tradition and culture, the kind of farming practice followed, size of the farms, amongst various other factors (Holmes, 1981). 


\section{J. Social Sci., 7 (4): 655-661, 2011}

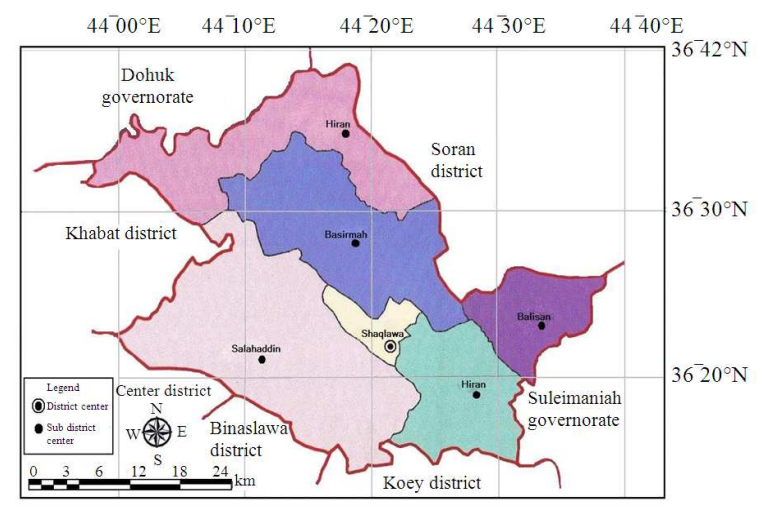

Fig.1: Geographical location and administrative divisions of shaqlawa district

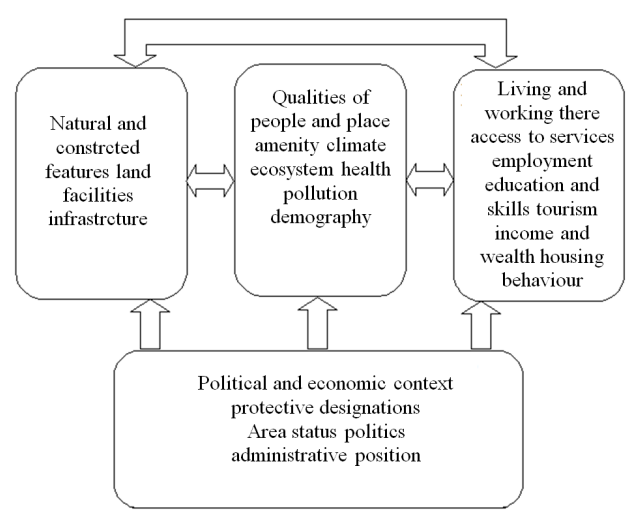

Fig. 2: A contextual framework for characterizing rural areas showing the kinds of data needed to capture key aspects of rural conditions ( Hughes and Huby, 2002). Here we find that socio-economic characteristics are one of the key factors for comprehending the essence of a rural community. Thus, we find that to comprehend the conditions within the rural communities it is essential to integrate socio economic aspects within the rural studies, as it would give a more holistic approach to the study of the entire rural scenario

Rural population density also influences the markets for entrepreneurs and the chances for earning from doing study other than farming. In their research study, Smailes et al. (2002) theorized an original relationship between rural density, which is an independent variable and other characteristics of the rural communities, which are the dependent variables. In their study, the authors found positive correlation between the rural population density and the total population; the mobility rate of the community members; industrial workforce and ratio of non-native population. Negative correlations were found with the number of people working within the primary industry, spatial area of the rural community, the masculinity proportion and the fertility ratio. The authors additionally found in their researches conducted mainly in the Australian context that rural population density remains correlated at a significance of 0.01 levels with the aforementioned variables, along with factors like youth dependency factor, unemployment proportions and ratio of the population below 15 years of age (Smailes et al., 2002).

Although there are a dearth of studies into the dimension of rural population density, whatever researches have been conducted into the matter, shows us that, there is a close link between the rural population density and socio-economic characteristics of rural communities and the two factors are mutually interdependent.

The study area: The idea of this research had come out from Author's interest about rural development studies. This research will continue study from previous researches done from the author in the specific area. The previous researches had identified several opportunities for rural development in the area. Therefore the researcher now will attempt to identify and analyze one specific sector of rural community, which is rural density. Shaqlawa district, located in the central part of Erbil state and is sub-divided into five sub-districts, namely, Harir, Basirmah, Hiran, Balisan and Salahaddin which shares borders with Swran districts to the north, Suleimaniah governorate and Koey district to the east and Dohuk governorate to the west, Dashty hawler district to the south, Fig. 1. Shaqlawa district has a total land area of 1787 square kilometers covering about $12 \%$ of the former Erbil governorate total land area which is about 14471 square kilometers. Farming activities take up about $52 \%$ of the total district land, while other uses are grazing $32 \%$ and forests $16 \%$.

Level of accuracy of any studies is highly dependent on the design of methodology used. The researcher looks into the method that will employ in this study. It deals with the procedure by which pertinent data will collect and analyze.

This research will examine the effect of rural population density on socio economic characteristics of rural community in Shaqlawa district. It assesses the pattern of rural population density in order to discover the driving force behind these differences from point of view spatial core and peripheral of elements this of Shaqlawa rural community. 


\section{J. Social Sci., 7 (4): 655-661, 2011}

Table 1: Methods of data gathering

\begin{tabular}{|c|c|c|}
\hline Data gathering technique & Type of data and purpose & source \\
\hline Questionnaire survey & $\begin{array}{l}\text { Socio-economic data to } \\
\text { test certain relations }\end{array}$ & Sample households \\
\hline Interview & $\begin{array}{l}\text { Socio-economic data to } \\
\text { describe certain facts } \\
\text { and patterns such us the } \\
\text { land use systems }\end{array}$ & $\begin{array}{l}\text { Limited purposely } \\
\text { selected sample } \\
\text { households }\end{array}$ \\
\hline Group discussions & $\begin{array}{l}\text { Community level } \\
\text { information to identify } \\
\text { the prevailing } \\
\text { livelihood and understand } \\
\text { local context at exploratory level, } \\
\text { identify local } \\
\text { wealth ranking } \\
\text { criteria and get a } \\
\text { limited data to use as a } \\
\text { reference against which } \\
\text { household level data } \\
\text { are checked }\end{array}$ & $\begin{array}{l}\text { Sample and non } \\
\text {-sample households }\end{array}$ \\
\hline Focus group discussions & $\begin{array}{l}\text { Fertility and gender } \\
\text { related issues }\end{array}$ & non-sa \\
\hline $\begin{array}{l}\text { Review of reports, policy } \\
\text { information }\end{array}$ & $\begin{array}{l}\text { Secondary data to } \\
\text { documents and publications } \\
\text { local offices }\end{array}$ & $\begin{array}{l}\text { Government, NGOs } \\
\text { get genera }\end{array}$ \\
\hline & $\begin{array}{l}\text { related to the study and to be } \\
\text { used for triangulation purpose }\end{array}$ & and universities \\
\hline
\end{tabular}

To this end purposive stratified sampling of respondents includes all households member (household head, wives, children and parent). The component of analysis for this research is the households as indicated in Table. 1. A household is a group of people sharing common entrance and other services. This is because of the Kurdish practice of extended environment family dwelling makes it difficult for a visitor to easily identify extend of each household's dwelling unit. The data gathering also includes: Group discussions, Focus group discussions, Review of reports, policy documents and publications as indicated in Table. 1.

Rural population density as an indicator of demographic and socioeconomic structure: Smailes, Argent and Griffin in their research study studied in details the relationships between the rural population density and the socio-economic structure of many of the rural communities in Australia. In their survey, they found that the rural population density serves to form good indicators of the demographic and socio-economic structure of a rural community and subsequently they framed the following hypotheses:

a) Low rural population density is correlated with greater spatial dimensions of the rural communities, with a greater distance between the neighboring towns and this forms the basic concept within the central place theory, the general truth can be seen by looking at any road map or topographical maps (Smailes et al., 2002)

b) The higher spatial dimensions of the local social systems within less dense areas compensate partly for the low population density. Thus, the lower rural population density, will implicate smaller total population size of the communities (ibid). c) Low rural population density is correlated with a low available rate of labor force participation. "This is expected mainly because in sparsely populated rural areas, numbers of females in the formal job market are likely to be low for a variety of reasons, including the relative shortage of both full time and part time nonfarm jobs, particularly for women and long commuting distances for the few jobs available" (ibid).

d) Low rural population density is generally corelated with low figures, but high densities of the labor force that study in farms. Rural population density highly affected by the productivity value of the land. In highly populated rural areas, farms will be smaller with larger absolute percentage of farmland workforce, a high rural population is most likely to create better opportunities for other kinds of non-farming enterprise to function profitably, so in such cases the rural community starts relying less on agriculture alone (ibid).

e) High rural densities are naturally associated with "high levels of both occupational and industrial diversity of the population" (ibid). Thus, highly populated areas will attract more businesses (other than farming) and more people into the area, thus creating a greater range of niches that can yield greater productivity for the entrepreneurs.

f) Low rural population density signifies lower proportions unemployed workforce within that locality. This is primarily owing to the fact that in sparsely populated areas, jobs being few and with a lack of services and amenities, those looking for jobs tend to migrate from that area. Areas having higher populations and with better services amenities are more likely to attract the migrant population thus giving rise to situation where many of the local people may remain unemployed.

g) In areas of low rural density the masculinity ratio of the population (males per 100 females) will tend to be high" (Smailes et al., 2002).

h) Low population density is generally associated with low proportions of the non-native population or people of foreign origin, owing to a lack of amnesties and services provided (ibid).

i) Areas having low rural population density will have low proportion of the population that may have changed address within the past 5 years. This is owing to the fact that the sparely populated areas will also have more percentage of out-migration as compared to inmigration, since once again a lack of amenities and services provided will attract very few migrants (ibid).

j) Low rural density will tend to be associated with a high fertility ratio (children under 5 per 100 women aged 15-44)...Low density is likely to correlate with high ruralilty, isolation, a low proportion of exurban 


\section{J. Social Sci., 7 (4): 655-661, 2011}

immigrants and the longer retention of established behaviors" (ibid).

k) Low rural population density tends to show a low proportion of the population under 15 years if age (ibid).

Importance of socio-economic aspects and activities in rural studies: Sustainable development demands that the social and economic needs of rural communities be considered in relation to concern for environmental protection. Such protection is only likely to be effective if it takes into account the various uses made of the countryside by the people who live there. Socioeconomic is an umbrella term with different usages, in many cases socioeconomics focus on the social impact of some sort of economic change. Such changes might include a closing factory, market manipulation, the signing of international trade treaties, new natural gas regulation,. The goal of socioeconomic study is generally to bring about socioeconomic development, usually in terms of improvements in metrics such as Gross Domestic Product (GDP), life expectancy, literacy, levels of employment. While specific research on the Rural population have on the immigration and movement remains a priority, attempts at improving the understanding of community socioeconomic systems and policies concerned should not be overlooked. Models may have been developed to analyze various community approaches, but the basic data on the underlying aspects affecting the whole system and understanding of the role of population structure, socio-economic backgrounds and community behaviors and perceptions of the public on rural studies should be of equal importance.

Socio-economic aspects of rural conditions can be captured using information about demographic patterns, housing, economic activity, travel and access to services, deprivation public health and neighborhood characteristics.

Impact studies differ in terms of geographic coverage, scale of analyses and approach adopted in measuring impacts. Accordingly, the scale of analyses varies among different studies, ranging from household to village, region, national to international levels. The approaches adopted to study the socio-economic impacts of irrigation in various studies can be classified into three major categories: (1) 'before and after' comparisons; (2) "with and without" comparisons and (3) "more and less", comparisons (Hussain and Hanjra, 2004).

Lately a large number of research scholars and experts have recognized the fact that all researches undertaken and public policies framed for the rural areas, must take into cognizance the account of the interactions that take place between the social, environmental and economic factors, within the local rural population. In the Rural White study it has been clearly mentioned that that the character of the rural areas hold great importance and can be viewed as environmental and economic assets Department of the Environment, 2000. The World Development Report 2009 gives us a detailed review where it portrays the environmental aspects as being a driver of economic activities, while also putting certain constraints upon the economic activities. Here the report linked the socioeconomic and environmental aspects of a rural community and suggested that the natural capital must be safeguarded Thus, within rural studies it is essential that one understands the basic socio-economic aspects of the community in order to provide suitable public policies and better public amenities. Socio-economic characteristics are one of the key factors for comprehending the essence of a rural community, Fig. 2.

Owing to the strong penetrative forces of globalization, the social research trends, including the ones that are exploring rural communities, are largely affected by many external factors (non-rural and foreign). These factors include the consumers; the regulatory bodies; the citizens; as well as various other forces triggered by the economic globalization, which has led to a blurring of the borders between the rural and non-rural zones. The modern drivers of change, as emerging from a globalised world of trade market, are, 'capital' and 'labor,' thus, making it imperative for any community that desires to improve its living and working conditions, to take cognizance of the socioeconomic factors and activities. For those studying rural studies, it is now essential in the context of a globalised world to study the socio-economic aspects of the rural communities in order to make better provisions and study out more effective framing of public polices, for the betterment of the rural communities. Rural governance is another topic that has gained importance recently and to comprehend the essence of good governance within the rural communities, one must first comprehend the basic framework on these communities function. Any community framework in order to operate effectively must base its foundations or pillars on the cultural, social and economic factors, thus, making it imperative that in order to efficiently govern, frame public polices and even to comprehend the complex matrix of the rural population, one must be well aware of the socio-economic characteristics and the demographics of these areas.

\section{CONCLUSION}

From the above review, it stands out clearly that rural population or settlement density is a very important 
factor or variable in identifying, delineating, analyzing and categorizing the rural communities. The concept of the rural population and the nature of these settlement densities are essential variables as one tries to comprehend the important factor in understanding the socio-economic, the population density and the settlement matrix of the sparsely populated rural areas, where the thin and decreasing population densities presents both theoretical and practical problems for those involved in rural planning. Rural population density has a strong influence over the socio-economic and demographic characteristics of the various nonurban communities, especially in the developed world and forms to be a fundamental variable within the realms of planning and public policy framing. Thus, we find that study of rural population density is an essential subject in order to develop these sparsely-populated areas better. However, a closer look at this subject of rural population shows us that not much study has been done in this line owing to the complex nature of the population density. The complex nature of population density also implicates the involvement of the socioeconomic, environmental and historical factors that help to create a specific density spectrum and kind. As shown by the researchers the rural population density has significant effects on the main attributes of the rural communities. The researchers have also shown that the rural population densities have a large influence on the socio-economic opportunities available to the people living in the non-urban regions in a majority if the developed countries, globally. Though one cannot deny the significance of the rural population density study, yet much remains to be done in this arena.

\section{REFERENCES}

Argent, N.M., P.J. Smailes and T. Griffin, 2005. Tracing the density impulse in rural settlement systems: a quantitative analysis of the factors underlying rural population density across southeastern australia, 1981-2001. Populat. Environ., 27: 151-190. DOI: $10.1007 / \mathrm{s} 11111-006-0018-1$

Bahr, J., C. Jentsch and W. Kuls, 1992. Bevölkerungsgeographie. 1st Edn., Walter de Gruyter, ISBN: 3110088622, Berlin, pp: 1158.
Berry, B.J.L., 1967. Geography of Market Centres and Retail Distribution. 1st Edn., Prentice-Hall, Prenton, pp: 146.

Fonseca, J.W. and D.W. Wong, 2000. Changing patterns of population density in the united states. Professional Geograp., 52: 504-517. DOI: 10.1111/0033-0124.00242

Irving, H. and R. Davidson, 1972. A working note on the measurement of social interaction. Trans. Barnett Society, 9: 7-19.

Holmes, J., 1981. Sparsely populated regions of Australia. In: Settlement systems in sparsely populated regions, R. Lonsdale and J. Holmes, (Eds.). Pergamon, New York, pp: 70-104.

Hughes, R. and M. Huby, 2002. The application of vignettes in social and nursing research. J. Adv. Nurs., 37: 382-386. DOI: 10.1046/j.13652648.2002.02100.x

Hussain, I. and M.A. Hanjra, 2004. Irrigation and poverty alleviation: Review of the empirical evidence. Irrigat. Drainage, 53: 1-15. DOI: 10.1002/ird.114

Robinson, A.H., J.B. Lindberg and L.W. Brinkman, 1961. A correlation and regression analysis applied to rural farm population densities in the great plains. Annals Association Am. Geograp., 51: 211221. DOI: 10.1111/j.1467-8306.1961.tb00374.x

Saglie, I., 1998. Density and Town Planning: Implementing a Densification Policy. AHO, Oslo, ISBN: 8270711144, pp: 366.

Smailes, P.J., N. Argent and T.L.C. Griffin, 2002. Rural population density: its impact on social and demographic aspects of rural communities. J. Rural Stud., 18: 385-404. doi:10.1016/S07430167(02)00033-5

Smailes, P.J., 1996. Demographic response to rural restructuring and counterurbanisation in south australia, 1981-1991. Int. J. Populat. Geogra., 2: 261-287. DOI: $10.1002 /($ SICI)10991220(199609)2:3<261::AID-IJPG38>3.0.CO;2-L

Theodoropoulou, H. and P. Kaldis, 2008. Changes in rural areas and regional development. J. Soc. Sci., 4: 275-279. DOI: 10.3844/jssp.2008.275.279

Tuan, Y., 1977. Space and Place: The Perspective of Experience. 1st Edn., University of Minnesota Press, ISBN: 0816608849, pp: 235. 